\title{
The mystery behind how EFL novice teachers should behave to manage their classroom enviroment effectively and empatheticly
}

\section{Zahra Zohoorian}

Islamic Azad University, Mashhad Branch, Mashhad, Iran.

Email: marjan.zohoorian@yahoo.com

\section{Akram Faravani*}

Islamic Azad University, Mashhad Branch, Mashhad, Iran, 09155054359

afaravani@yahoo.com

\section{Abstract}

very EFL classroom can possibly become
entrenched in the dynamics of the teachers,
vulnerable students, and classroom climate. Qualities such as empathy can be forgotten by teachers as stereotypes, prejudices, and preconceptions emerge. Therefore, the development of empathetic strategies and positive attitudes towards language learning among students can be improved by teachers with empathic abilities in the classroom, where the classroom climate plays an important role. Enhancing the strategies related to empathy development among novice teachers may help to create better conditions for care and higher academic expectations. In addition, empathy is a necessary skill for teachers to effectively manage their classrooms. Research supports empathy's importance in English language teaching as it promotes positive outcomes in the classroom both intellectually and emotioally. It also foments a culturally sensitive class environment. As teaching with empathy can enhance teacher effectiveness, this review paper introduces some necceaary empathy related guidelines for novice teachers to apply so that they can develop their effectiveness in teaching. The results are discussed in the light of guidelines for beginner teachers.

Key Words: Empathy, Classroom Management, Classroom Environment, Teacher Effectiveness 


\section{Introduction :}

The teachers' traits have a primary role in their success in educating their students. Thus, delving into the related characteristics of effective teachers such as various traits, features, and personality characteristics can provide a list of guidelines for novice teachers to improve their quality of teaching.

Obviously, any chief transformation in educational settings can only be achieved through the quality of teachers' effectiveness and performance because they are directly involved in all matters related to students' life-long learning. Thus, the training of human resources especially in educational settings is the key where language education is no exception (Mirheydari, 2007). On the one hand, the most important human resources in education are teachers whose effectiveness may depend on an array of factors which may either be external to the teacher such as a school's particular system and the students or internal such as the teachers' characteristics, personalities, abilities, etc. (Marwat, 2012).On the other hand, as Hasan (2004, as cited in Ahmed et.al, 2012) states environmental factors also affect a teacher's performance which can lead to teachers' effectiveness or failure. Among such internal and external environmental factors which mainly influence the teachers' effectiveness in teaching, the focus of this study is on empathy as an internal and the classroom environment as an external factor.

\section{Review of the Literature}

Environmental and affective factors have essential roles in the teachers' quality of teaching as they may affect effectiveness or failure. 
Kaufman (2009) proposes mega planning and argues that any organization such as educational institutes and schools can be the means to ends in the society and they,therefore, add value to all that stakeholders do in every society to increase effectivenss. The stakeholders for the educational context include the students and teachers who need to improve in the educational system. In other words, Kaufman's (2009) idea relies on the fact that improvement requires reliance on the current realities in the educational context and that there needs to be a shift from 'what is' to 'what should be' (Kaufman et. Al, 2003). Kaufman (2009) adds that success and effectiveness may be achievable through this model if one realizes the fact that yesterday's understanding, methods, or concepts may not always be appropriate for tomorrow. Considering Mega thinking and planning as two matters of choice, Kaufman (1999) claims that success and effectiveness can be created based on what one finds as reality. Thus, investigating the existing relavant reality and gaps in educational contexts can help to have a better future.

As mentioned, any chief transformation in education can only be achieved through the quality of teachers' effectiveness and performance because they are directly involved in all matters. Thus, training and helping novice teachers to be effective in their classrooms is the key to professional development (Mirheydari, 2007).

\section{Techer Effectiveness}

As a rule, it does not seem to be difficult to draw up a list of qualities of an effective English instructor. The list probably includes: having requisite knowledge and skills in 
English and pedagogy, demonstrating the ability to sustain learners' motivation and to involve them

productively in interaction, being able to introduce students into ways of thinking and cultural practices and helping them to react upon their own practices, plus some personal or professional characteristics, such as patience (Nemati \& Kaivanpanah, 2013).

However, the list does not seem to be comprehensive as numerous internal and external factors may affect a teacher's effectiveness. Teacher quality can be a complex phenomenon and there is little consensus on how to measure or define it. There are many perspectives to be taken into account including the teacher qualifications, the teaching process itself, and the output of teaching.

According to Aspy and Roebuk (1970), effective teachers motivate students to get higher achievements and enable them to be innovative. Emmer (1981) relates effectiveness to the teacher's paying attention to the needs, interests, problems, and achievements of the students. In the same vein, Hunt (2009) defines teacher effectiveness as a combination of all the characteristics, competencies, and behaviors that a teacher will employ to help students get to their desired targets. As far as the teaching experience is concerned, according to Chestnut and Marks (1994), experienece seems to be more insightful toward their strong and weak points in their teaching performance.

Among all the scholars who list the characteristics, Brown (2004) focuses on the required behavior for effective teaching and learning and argues that interaction between students and teachers, mutuality and cooperation among students, active learning procedures, provision of 
swift feedback, emphasis on time on tasks, and consideration of varied talents and learning ways are the major traits of an effective teacher.

Also, Tan de-Ramos (2011) contends that "teaching is a specialized skill that involves not only expertise in the given academic field but also the ability to create for the learners an environment where they can get optimal learning gain" (p.71).

There have been several approaches based on which teacher effectiveness has been measured. However, "measuring teacher effectiveness has remained elusive in part because of the ongoing debate about what an effective teacher is and does" (Goe, et. al, 2008, p. 2). This measurement can be conducted from the teachers' perspectives, the students' perspectives, or the administrators' perspectives. But, while the students are closely engaged in the process of teaching and learning, they can be very helpful in the enhancement of teaching and teachers' quality (Calagus, 2012). Similarly, Berk (2005) maintains that seeking students' ratings is primary as they may act as the sources of evidence for the effectiveness of teaching. Likewise, Goe, et. al (2008) refer to students as the direct customers of the service given by the teachers and thus their evaluation of the teacher's performance can be relied on due to the good position of evaluation they have.

As mentioned before, teacher effectiveness can be measured in terms of the students' views. One famous framework through which teacher effectiveness can be measured by students is the one proposed and prepared by Calaguas (2012). This framework has an intensive review 
of the literature on teacher effectiveness. The constructs categorized into the measure designed by Calaguas include teaching-related behavior, subject matter expertise, relational expertise, and personality:

The teaching-related behavior includes believing in the potential of students, showing passion for teaching...observing norms of conduct in the teaching profession...,observing ethical conduct in the teaching profession, showing dedication to the teaching profession, serving as positive role model to students, commanding respect from students,eliciting enthusiasm among students when teaching, incorporating creativity in delivering of lessons, communicating ideas effectively, ... showing love for teaching while discussing, ..., making learning enjoyable for students, interacting with students during class discussions، ... welcoming students' participation in classroom discussions, encouraging students to be hardworking, using a variety of instructional strategies, observing flexibility of instructional style to be able to fit to the different needs of students,... taking into consideration students' moral development in lessons taught, ...setting realistic goals for students to accomplish...' showing keenness to inappropriate behaviors, correcting inappropriate behaviors, responding at once to issues involving discipline, ... giving importance to discipline in the classroom, not yelling at students, and trying to know the concerns of students who misbehave ( $p$. 15-16).

Moreover, Calaguas (2012) highlights that subject matter expertise entails the following:

Being prepared always when holding classes, showing mastery of lessons taught, knowing a lot of information about lessons taught, manifesting expertise in lessons 
taught, sharing a lot of interesting ideas related to lessons taught, displaying authority when teaching, knowing how to answer questions raised about lessons taught, showing, thorough understanding of lessons taught,sharing information that is relevant only to lessons taught, and exhibiting the ability to a teach a lot of academic subjects (p.16)

Concerning relational expertise, Calaguas (2012) posits that effective teachers not only display kindness and friendly attitude toward students but also respect and accept them. Also, regarding the personality construct, effective teachers manifest charisma, grace under pressure, outgoing personality, predictability of their actions, and finally reflection.

In addition, There are some explicit characteristics which are necessary for teachers who desire to teach effectively. One quality for good teachers is having excellent communication skills. Thus, the most important quality for a teacher is not just knowledge, but sharing the knowledge. That is, in order to create successful learning environments, great teachers need to be able to build sympathetic and empathetic relationships with their students. Consequently, it can be implied that the best teachers are the ones who understand the importance of empathy and supportive environments (Camacho, Coto, \& Jensen, 2021; Zohoorian \& Zeraatpishe, 2020).

\section{Teachers' sense of Empathy}

Empathy is a success determining factor in the process of foreign language learning (Wang, 2005) as it takes a major role in establishing communication (Chen, 2013). Empathy is not a new concept and it has been defined 
throughout history in different fields including psychology and linguistics or even pragmatics (Khorrami, 2016). Empathy is not only important on the part of the teachers but also on the part of the students as its proper level will have a positive effect on language learning (Chen, 2008). Moreover, among all the several impacting factors, empathy can provide a positive learning situation and environment (Cherniss, 2000; Wang, 2005). Empathy has also been associated with moral development as well as attitude (Hoffman, 2001).

Communication and understanding are two important issues in creating suitable rapport with the students; thus, for the development of the classroom environment a teacher needs to see through the students' eyes (Kyriacou,1986). As a result, empathy is an identical experiencing of the other person's situation (Cooper,2002). A teacher having high empathy can help her classroom environment as well. In the same vein, Bratton(2016) also emphasize the importance of sensitivity to other person's feelings, thoughts and situations. Moreover, Goleman (1998) stresses the importance of empathy as far as concentration on the individual differences in terms of emotions and beliefs are concerned. Besides, empathy may also include the sharing of 'joy or grief' (Bratton,2015 ,p.33). Accordingly, a prerequisite of teaching is empathy. Empathy is thus so important that Halamandaris and Loughton (2011, cited in Blašková, 2016) call it as one of the competences for an ideal teacher.

As far as teacher empathy is concerned, Soanes and Stevenson (2008) emphasize that emphatic communication from the teacher's side will lead to acceptance and greater understanding which will result in positive attitudes and a 
sense of belonging. Empathy is also known as a motivating factor (Blašková, 2016) which can help the teachers understand the students' emotional states.

Different scholars look at empathy from various perspectives. Generally, empathy has been investigated more according to theory rather than experience; however, it is extremely difficult to define and measure. Cooper (2002) considers empathy as quite a complex phenomenon which is intimately related to moral development and needs time. There are numerous explanations and definitions for Empathy as there are researchers or scholars who investigated it (Olivares, 2012), so there has not been an agreement on one definition.

Nevertheless, according to Demetriou, Wilson, and Winterbottom (2009), teacher empathy has been the focus of research most of the times rather than the student empathy as the teacher is viewed as a counselor or therapist and the student is viewed as a client. Thus, research needs to find the factors that contribute to the enhancement of teacher empathy as far as students' needs are concerned so that even novice teachers can identify the related factors and then control, manage, and finally respond.

However, it sould be emphasized that the teacher ability to express concern and take the perspective of a student involves both cognitive and affective domains of empathy.Several categories for empathy are proposed. The first one sees empathy has having two components including cognitive and affective (Blair,2005; Singer, et al, 2006). The former emphasizes the person's capability of perceiving and knowing other individuals' feelings (Zaki \& Ochsner, 2012). This component focuses more on the 
cognitive processes rather than the emotional reactions (Batson \& Powell, 2003). On the other hand, affective or emotional empathy focuses on the emotional response (Hoffman, 2001). While cognitive empathy relates to another person being separated from the source, emotional empathy needs aspects like attachment to the other persons (Halperin, 2015).

Other researchers define other components for empathy. For example Morse, et al, (1992) categorize them as moral, behavioral, cognitive, and emotive. One of the most comprehensive definitions and classifications is given by Davis (1983) who defines empathy as a multidimensional feature by categorizing it into the components including perspective taking, empathic concern, personal distress, and fantasy.

Several researchers have concentrated on empathy as an important and determining factor in developing proper rapport and successful communication, as well as effectiveness of the teacher. However, classroom environment is also vital in making a teacher effective. The reason is that emotional characteristics of the teachers are often cited as significant in creating the overall positive atmosphere in the classroom among which the most important ones are named as emotional stability and empathetic sensitivity (Stojijkovic \& Doskovi 2011). Classroom management as pedagogical leadership is considered as a determining factor for the outcome of schooling (Nazari, Zohoorian, \& Faravani, 2021). Accordingly, classroom management can be discussed as the creation of a safe, empathetic, and motivating environment (Joulide, 2020). 


\section{Effective Teachers' Classroom Environment}

Classroom learning environment quality has a fundamental effect on the learning engagement of the learners. It is also associated with the inclination of the learners to learn. Classroom environment can be studied and evaluated based on several concepts and ideas including the physical context, the relationship patterns between the teacher and the students, the psychological climate, and many other features (Faravani, 2021).

There is an array of techniques and methods to be employed by teachers to be efffective in their classroom environment. Researchers have conducted quantitative as well as qualitative methods and have used different designs including case studies, observant participation, naturalistic inquiry, systematic coding of classroom events and communication, etc (Fraser, 1998).

There are also several categorizations for classroom environment components based on the views of the researchers. Moos (1979) categorizes the areas in classroom environment research into relationship dimension (such as interpersonal relationships of students with peers and the teacher), personal development dimension (classroom members' individual characteristics), and system maintenance and change dimension (like control, order, or responsiveness). Another dimension categorization which is given by Fraser (2002) includes the components of student perceptions, classroom dimensions, student cohesiveness, teacher support, involvement, investigation, cooperation, etc. Other more recent approaches include components such as human resources, mental circumstances which relate to mutual 
relations as well as the surrounding environment (Andersone, 2017).

The earliest measures to evaluate classroom environment were developed in the US around 1960s. however, up to the present time many researchers and scholars have attempted to develop effective measures including Learning Environment Inventory (LEI) by Walberg and Anderson (1968), Classroom Environment Scale (CES) by Moos and Trickett (1974), and Individualized Classroom Environment Questionnaire (ICEQ) which was designed in Australia during 1980s (Fraser \& Goh, 2003).

Fraser and Fisher (1986) proposed personalization, independence, differentiation, participation, and investigation as the main constructs of effective classroom environment. Personalization refers to the interactive opportunities provided for students to interact with the teacher and the the concern for the personal welfare and social growth of the individual. Participation refers to the extent to which students are encouraged to be active and participate rather than be passive listeners. Also, independence refers to the extent to which students are allowed to make decisions independently and control their learning and behavior. Investigation means emphasis on the skills of inquiry and problem-solving. Finally, differentiation takes in to consideration the students' learning styles, interests, and rate of working.

The importance of positive classroom environment and empathy for an effective teacher

Based on the literature reviewed, it seems that the connection between teacher relationships and student 
outcomes is ubiquitous. In a widely publicized study, Deborah Roorda and her colleagues (2011) reviewed research from 99 studies around the world that examined the connections between teacher-student relationships in the classroom and student engagement. Clearly, positive teacher-student relationship includes different factors, one of which is empathy. Positive teacher relationships were a positive predictor of positive student engagement at every grade. That is, it enhances teachers' effectiveness. Interestingly enough, . Deborah Roorda et. Al, (2011) also concluded that the relationships were especially strong for both students who were at risk academically and for older students. So, evidence is mounting for a strong association between the quality of empathy and school performance.

It can be implied that students working with a teacher with low sense of empathy may be behind the students working with a teacher with a higher level of emapthy. If these losses accumulate, then students working with novice teachers with little knowledge about classroom environment and empathy would fall farther behind. In fact, Deborah Roorda et. Al, (2011) speculated that effective teachers who establish positive relationships with their students appear to be a powerful force in those students' lives.

Thus, it is recommended that novice teachers consider both intellectual and emotional support in their classrooms since students who feel stressed and anxious encounter problems when they try to learn. Obviously, teachers' support to students can build more confidence and so promote learning. "Emotional scaffolding includes the gift of confidence, the sharing of risk in the presentation of new 
ideas, constructive criticism, and the creation of a safety zone" (Mahn \& John-Steiner, 2002, p. 51-52).

Key suggestions for novice teachers to practice empathy in the classroom

A glance back through the literature suggests that teachers can be trained to show evidence of empathy as a professional disposition in their job. Warren (2014) concluded that empathy is a professional disposition applied by teachers to negotiate interactions with students and that it requires two phases of implementation: The first phase is the acquisition of new knowledge and the second one is the strategic negotiation of that knowledge and elucidation of learner feedback to make the required academic adjustments in subsequent student-teacher interactions.

Warren (2014) argues that the first phase of empathy's application in the effective teachers' professional classroom context includes perspective taking and empathetic concern. Therefore, effective teachers consider perspective taking by implementing "activities, strategies, rituals, and policies meant to obtain first person, microlevel knowledge of students" (p.412). It implies that for novice teachers, priority should be given to the "imagine other" modality of perspective taking. Moreover, empathetic concern highlights the fact that novice teachers should conduct behaviors that communicate a mutual "sharing of emotion, feeling, or experience with students" (p.412) .

Consequently, with regard to the first phase, a teachers' sense of empathy includes understanding of solidarity that exists among students' ideas, emotions, apprehension, and 
concerns and about their condition and the teacher's own ideas, emotions, apprehension, and concerns about the student's circumstance. Likewise, in order for novice teachers to successfully employ and develop perspective taking, Yilmaz (2007) claims that teachers should provide appropriate conditions so that students can:

- access authentic historical sources and engage in critical examination of those sources,

- have a balance of imaginative speculation and methodical investigation,

- relive the thoughts of past individuals through the heuristic of contextualization,

- examine, appreciate, and understand the perspectives of people in the past and render them intelligible to contemporary minds

- make reasoned evidential reconstruction in addition to taking a position to reconstruct a set of beliefs, values, goals, and attendant feelings that historical agents had,

- engage in sustained effort and thoughtful strategy to suspend their present world views when examining the past (p. 333-334)

Warren (2014) adds that the second phase refers to the strategic negotiation of new knowledge which can be acquired from the results of perspective taking and the fine-tuning of teachers' response to student feedback. Such feedback is outstandingly based on the application of empathy. In addition, in the second phase which is recursive, teachers are recommended to interpret "what they think they know about students and they translate that interpretation into their practice" (p.413) . 
Concerning empathy, Yilmaz (2007) claims that novice teachers should provide students with conditions to enable them to engage in empathy and develop their perspective taking skills. For example, to enhance empathy, students should be able to scheme their thoughts and emotions into a particular situation. Also, they should be able to utilize a range of reference materials and existing sources that are related to the topic of the study.

To foster empathy, professional development programs and training courses must "create opportunities for authentic learning on the part of the teacher" and "help them make sense of their own identities, culture, and biases so they are more equipped to help their students engage in this critical reflection" (Rieckhoff, et al., 2020, p. 54). That is, such programs may help teacher candidates to "learn pedagogical approaches that will help them make thoughtful connections with other students and sustain students' perspectives based in sociocultural differences in school contexts". This can be met through "building teacher empathy and culturally responsive engagement, and positioning teachers' as change agents in their classrooms" (p.55).

To sum up, reviewing the literature reveals that there are several approaches taken toward the definition, categorization, and measurement of the classroom environment. Some view it from the perspective of the students while others focus on the teachers and the physical environment. In this review, interaction, participation, control over behavior, skills needed for inquiry, and individualized learning styles and interests were considered as primary features of effective teachers' clasrooms. 
In this review, some useful guidelines were introduced to help EFL teachers to be more effective in their classrooms. The litearture supports that the teachers who apply empathetic strategies can lead to more positive attitudes among the students. Perspective taking is also crucial as it diminishes the prejudices in the classrooms. That is, empathic concern and perspective taking can be significant predictors of a better classroom climate. Due to the apparent influence of teachers on the students, teacher traning courses and workshops, aiming at improving the empathic abilities of students and teachers with a especial focuse on perspective taking, should be held to help novice teachers. Raising the understanding of teachers' influence and the importance of the relationship with each student should be the focus of such training sessions.

It can also be concluded that both verbal and nonverbal interaction between group members in the classsroom may ensure that empathy is maintained. Therefore, teachers should strive to preserve clear lines of communication with and among the pupils themselves. In other words, teachers should act as facilitators for free thought and expression. Empathy can be practiced through controlled group discussion and teacher led debates. Besides, teachers should pacify and accommodate in order to have an equable discourse in the class.

The social interaction between students needs to be positive and fair. Teachers should creat an atmosphere in the classroom in which all pupils feel that they have something to contribute and they are allowed to not only express themselves freely but also respond to the views of others in an appropriate way. This helps students to be sensetive to other people's views. However, such 
sensetivity may be built when students experience both confirmatory and contradictory perspectives. This, in turn, can lead to the development of empathy.

\section{Conclusion}

More recently, researchers agree that empathy is a professional disposition of effective teachers and that its application is likely to improve their teaching effectiveness. Empathy's relevance to the teaching profession has remained central to the human interactions between teachers and students throughout the years.

Importantly, novice teachers may share many concerns, such as knowing how to create positive classroom environment, maintaining classroom discipline, motivating students, accommodating differences among students, and more importantly being empathetic toward the students. Therefore, they may experience a kind of reality shock as they do not know how to deal with the problems. Therefore, they should become aware of the guidelines that help them to be effective through teachers training programs and workshops. Despite the fact that experience, hard work, and good support can help beginning teachers to gain empathetic strategies, this paper provided some effective hints regarding empathy. That is, the goal of this review paper was providing the knowledge and skills that may enable novice teachers to behave effectively and empathetically in their classrooms. Teaching English in the context of a class can be challenging for both teachers and students. The quality of the teacher- student relationship including the level of conflict with the learner, the learner's dependency on the teacher, and the teacher's affection for the learners predict a number of academic 
and behavioral outcomes. Even when teachers consider the gender, ethnicity, cognitive ability, and behavior ratings of the student, the relationship with the teacher may still predict aspects of school success. Consequently, teachers' sense of empathy is very contributing as it can help students with important behavior problems specially in the early years to have less problems later in school.

Despite the bulk of research in the area of empathy, there still needs to be more research on how to capture the complexity of empathy, how to foster empathy and how to intersect teachers' own conceptions of empathy with their professional decision-making. More systematic observations, empirical research, and interviews with students and teachers are needed to augment our understanding of the empathy application process.

\section{Refrences}

- Ahmed, M., Hussain, I., Ahmed, S., \& ud Din, M. Q. (2012). A study of the factors affecting the professional performance of teachers at higher education level in Khyber.

- Andersone, R. (2017). The Learning Environment in Today's School in the Context of Content Reform of Curriculum. Jelgava, (12-13 May), 17-22.

- Aspy, D, F. Roebuk, F. N. (1970). Response Surface Analysis. National consortium for humanizing Education, Interim Report. Rockville: National Consortium for Humanizing Education Study.

- Batson, C. D., \& Powell, A. A. (2003). Altruism and prosocial behavior. Handbook of psychology. New York: Plume.

- Berk, R. A. (2005). Survey of 12 strategies to measure teaching effectiveness. International Journal of Teaching and Learning in Higher Education, 17 (1), 48-62.

- Blair, R. J. R. (2005). Responding to the emotions of others: dissociating forms of empathy through the study of typical and psychiatric populations. Consciousness and cognition, 14(4), 698718. 
- Blaskova, M. (2016). Empathy versus apathy in motivational decision making of University teachers. New Trends and Issues Proceedings on Humanities and Social Sciences, 2(11), 53-65.

- Bratton, B. H. (2016). Bad Mood: On Design and 'Empathy'. Architectural Design, 86(6), 96-101.

- Brown, H. D. (2004). Teaching by Principles: Language Assessment. New York: Pearson Education.

- Calaguas, G. M. (2012). Teacher effectiveness scale in higher education: Development and psychometric properties. International Journal of Research Studies in Education, 1(1), 1-18.

- Camacho, H., Coto, M., \& Jensen, S. P. (2021). Participatory methods to support knowledge management systems design in educational environments. International Journal of Knowledge Management Studies, 12(1), 34-54.

- Chen, L. (2008). The Effect of Empathy on College English Speaking. Asian Social Science, 4(8), 142.

- Chen, C. (2013). Empathy in language learning and its inspiration to the development of intercultural communicative competence. Theory and Practice in Language Studies, 3(12), 2267.

- Cherniss, C.(2000). Emotional Intelligence: What's it and why it matters? Society for Industrial and Organizational Psychology, 4(2), 15-21.

- Cooper, B. (2002). Teachers as moral models? The role of empathy in teacher/pupil relationships (Unpublished $\mathrm{PhD}$ thesis). Leeds: Leeds Metropolitan University.

- Davis, M. H. (1983). Measuring individual differences in empathy: Evidence for a multidimensional approach. Journal of personality and social psychology, 44(1), 113.

- Roorda, D. L., Koomen, H. M., Spilt, J. L., \& Oort, F. J. (2011). The influence of affective teacher-student relationships on students' school engagement and achievement: A meta-analytic approach. Review of educational research, 81(4), 493-529.

- Demetriou, H., Wilson, E., \& Winterbottom, M. (2009). The role of emotion in teaching: Are there differences between male and female newly qualified teachers' approaches to teaching? Educational Studies, 35(4), 449-473. 
- Emmer, E.T. (1981). Teacher's Manual for the Junior High Classroom Management Improvement Study. Austin: R\&D Center for Teacher Education, University of Texas.

- Faravani, A. (2021).. Ghom: Farzanegane Danesh Publication.

- Fraser, B. (1998). Classroom Environment Instruments: Development, Validity and Applications. Learning environments research, 1(1), 7-34.

- Fraser, B. J. (2002). Learning environments research: Yesterday, today, and tomorrow. In S. C. Goh \& M. S. Khine (Eds.), Studies in educational learning environments: An international perspective (pp. 1-26). Singapore: World Scientific.

- Fraser, B. J., \& Fisher, D. L. (1986). Using short forms of classroom climate instruments to assess and improve classroom psychosocial environment. Journal of Research in Science Teaching, 23(5), 387-413.

- Fraser, B.J., Goh, S.C. (2003) Classroom Learning Environments. In: Keeves J.P. et al. (Eds) International Handbook of Educational Research in the Asia-Pacific Region. Springer International Handbooks of Education, 11. Springer, Dordrecht

- Goe, L., Bell, C., \& Little O. (2008). Approaches to evaluating teacher effectiveness: A research synthesis. National Comprehensive Center for Teacher Quality.

- Goleman, D. (1998). The emotionally competent leader. In The Healthcare Forum Journal (Vol. 41, No. 2, pp. 36-38).

- Halperin, E. (2015). Emotions in conflict: Inhibitors and facilitators of peace making. London: Routledge.

- Hoffman, M. L. (2001). Empathy and moral development: Implications for caring and justice. Cambridge: Cambridge University Press.

- Hunt, B. C. (2009). Teacher effectiveness: A review of the international literature and its relevance for improving education in Latin America. Washington, DC: PREAL.Ickes, W. (Ed.) (1997) Empathic accuracy. New York: The Guilford Press.

- Joulide, Sh., Faravani, A.,\& Boori, A.A. (2020). Conjuring up the correspondence of high-school students' self-determination and classroom climate with reading achievement, English Language Teaching Educational Journal, 3(3), 198-210. 
- Kaufman, R (1999). Mega planning: Practical tools for organizational success. CA: Sage Publication.

- Kaufman, R., Oakley-Browne, H., Watkins, R., \& Leigh, D. (2003). Strategic planning for success: Aligning people, performance, and payoffs. New York: John Wiley \& Sons.

- Kaufman, R. (2009). Mega thinking and planning: An introduction to defining and delivering individual and organizational success. Performance Improvement Quarterly, 22(2), 5- 15.

- Khorrami, N. (2016). The Relationships among Willingness to Communicate, Big Five Personality Traits, and Empathy: A Case of Iranian Intermediate EFL Learners (Master's thesis). Mashhad: Islamic Azad University.

- Kyriacou, C. (1986). Effective teaching in schools. UK: Simon and Schuster.

- Mahn, H., \& John-Steiner, V. (2002). The gift of confidence: A Vygotskian view of

- emotions. Learning for life in the 21st century: Sociocultural perspectives on the future of education, 46-58.

- Marks, L. L. (1994). The effectiveness of music teacher preservice training in California's

- colleges and universities: Professional preparation and teacher retention (Doctoral dissertation, University of Southern California).

- Marwat, A. K., Shah, I., Khan, S., \& Gul, S. (2012). Teachers' stress, performance \& resources:the moderating effects of resources on stress \& performance. 2(2), 12 .

- Mirheydari, A. (2007). Teacher Stance in Educational Systems. Isfahan: Research center in Education Organization.

- Moos, R. (1979). Evaluating educational environments: procedures, measures, findings and policy implications. San Francisco: Jossey-Bass.

- Moos, R. H., \& Trickett, E. J. (1974). Classroom environment scale: Manual.

- Morse, J. M., Anderson, G., Bottorff, J. L., Yonge, O., O'Brien, B., Solberg, S. M., \& McIlveen, K. H. (1992). Exploring empathy: a conceptual fit for nursing practice?. Image: The journal of nursing scholarship, 24(4), 273-280. 
- Nazari, M., Zohoorian, Z., \& Faravani, A. (2021). Patterns of teaching empowerment and classroom management among successful EFL teachers, International Journal of Research in Teacher Education, 12 (2), 36-52

- Nemati, M., \& Kaivanpanah, S. (2013). 'He or She?'Examining Cultural Influences on Iranian Language Learners' Perceptions of Teacher Efficacy. In Researching Cultures of Learning (pp. 203221). Palgrave Macmillan, London.

- Olivares, G. (2012). Does empathy make a difference in the foreign language classroom? Alicanto. Journal of Literature, Linguistics and Education, 5, 62-72.

- Rieckhoff, B. S., Ockerman, M., Proweller, A., \& Wolfinger, J. (2020). Building Teacher Empathy and Culturally Responsive Practice Through Professional Development and SelfReflection. Journal of Vincentian Social Action, 5(2), 8.

- Singer, T., Seymour, B., O'Doherty, J. P., Stephan, K. E., Dolan, R. J., \& Frith, C. D. (2006). Empathic neural responses are modulated by the perceived fairness of others. Nature, 439(7075), 466-469.

- Stojiljkovic, S., Djigic, G., \& Zlatkovic, B. (2012). Empathy and teachers" roles. Procedia-social and behavioral sciences, 69, 960966.

- Tan de-Ramos, J. (2011). Teacher effectiveness in academic research writing: An exploratory factor analysis. The Assessment Handbook, 4(2), 71-82.

- Walberg, H. J., \& Anderson, G. J. (1968). Classroom climate and individual learning. Journal of educational Psychology, 59(6p1), 414.

- Wang, G. L. (2005). Humanistic approach and affective factors in foreign language teaching. Sino-US English Teaching, 2(5), 1-5.

- Warren, C. A. (2014). Towards a Pedagogy for the Application of Empathy in Culturally Diverse Classrooms. The urban review, 46(3), 395-419.

- Zaki, J., \& Ochsner, K. N. (2012). The neuroscience of empathy: progress, pitfalls and promise. Nature neuroscience, 15(5), 675680.

- Zohoorian, Z., \& Zeraatpishe, M. (2020). Teacher Interaction and Empathy: An Investigation among Effective English Language 
Teachers, International Journal of Research in Teacher Education, 11 (2), 35-48.

- Yilmaz, K. (2007). Historical empathy and its implications for classroom practices in schools. The History Teacher, 40(3), 331337. 